\title{
Design and Fabrication of Ramp Attachment for Wheelchair
}

\author{
Arish Ibrahim* \\ *(SMIIE, Masters in Industrial Engineering, Teacher in Mechanical Engineering, India \\ Corresponding Author: Arish Ibrahim
}

\begin{abstract}
The manual wheel chairs are widely used because of its availability and economic factors even if it faces the limitation of accessing curbs and stairs. Some of the advanced electronic wheelchairs having the climbing feature but those wheelchairs are not affordable to common people and not suitable for daily usage in rough terrains. This paper proposing a ramp attachment design that makes the normal wheelchair to climb the curbs on the streets and accessing the buildings without ramp facility. The design concept doesn't make any modifications in the basic design of wheelchair as it involves just an attachment of ramp and sliding mechanism. The proposed design can also applicable to shopping carts or any other people transferring devices for meeting the specific needs.
\end{abstract}

Keywords: Curb climbing, ramp, stair climbing, Sliding mechanism, wheelchair.

\section{INTRODUCTION}

The manual wheelchairs are widely used because of its availability and economic factors even if it faces the limitation of accessing curbs and stairs. Some of the advanced electronic wheelchairs having the climbing feature but those wheelchairs are not affordable to common people and not suitable for daily usage in rough terrains. Many assisting mechanisms have been developed to enable the manual wheel chair to climb the curbs and having so many limitations and complexities. There are some curb assistive mechanisms like powered curb climbers, track based climbers, wheel cluster based and dual wheel cluster based stair or curb climbers exists and various works published on these recent advances. Track based stair climbers is one of the common one among these advances that facilitates autonomous stair climbing and suitable to most outdoor and indoor usage. There is also a simple ramp attachment design also applied by arranging a trough-shaped wheel ramps and telescoping articulating control rods intended to allow a wheelchair bound paraplegic to quickly ascend and descend single steps or curbs[1]. This paper provides a simple solution to the curb barrier which is inexpensive, light weight and can be added to standard manual wheelchairs or trolleys with only a minor modification. The design can be applied to shopping carts, material transferring trolleys and other small wheeled devices.

\section{DESIGN CONCEPT}

The main objective of curb climbing mechanism is that ramps for overcoming curbs and can be added to standard manual wheelchair with minor modifications. The proposed design is simple as it consists of two ramps with connecting rods. The connecting rods were attached to the side frame of the wheel through a small rod with rolling or sliding hole for it. The small rod can be either welded or clamped to the side frame of the wheelchair. The ramp can be locked back to the side frame after the use.

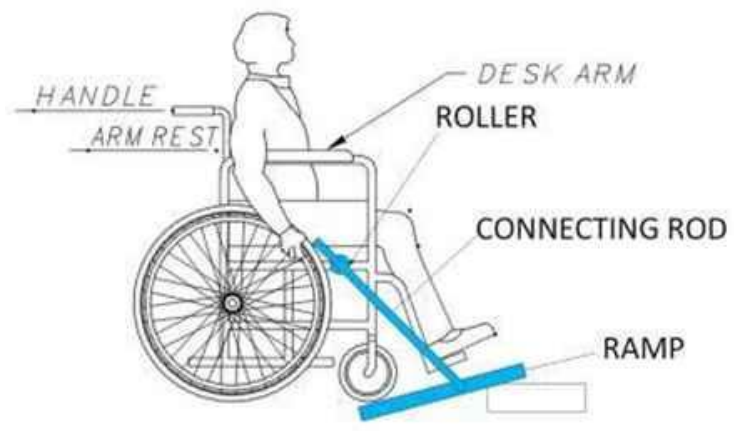

Fig.1 Ramp attachment design concept

The ramps can be locked securely on the sides of wheelchair using a locking nut and it can be removed for deploying. The ramp attachment can be operated either by the user or accompanying person when it requires. There is no need of lubrication and Aluminum rod can slide smoothly through the hole. The ramp attachment is fabricated with aluminum and a rubber layer added to the ramps for avoiding any slippage. 


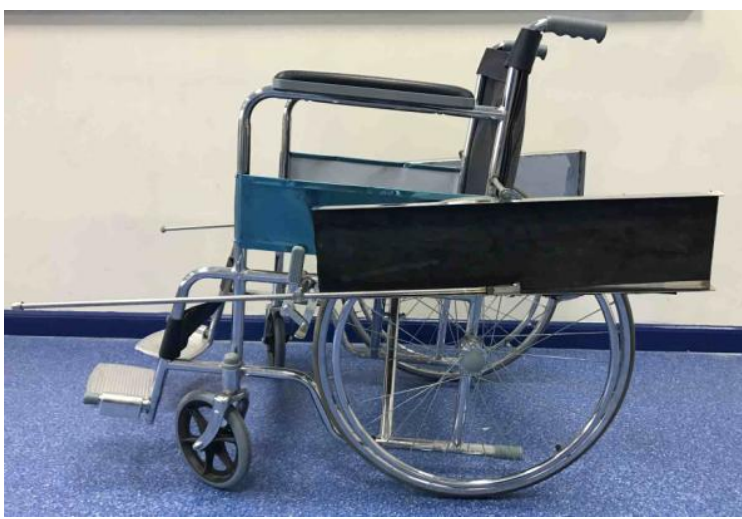

Fig.2 Ramp attachment for standard manual wheelchair.

\section{FABICATION AND WORKING}

Initially the ramps on both sides unlocked by loosening the lock nuts and position it according to the height of curb using the connecting rod. Once the ramps are firmly placed on the curb initiate the climbing process by self or with the help of accompanying person. The slider mechanism facilitates the climbing of wheelchair through the ramp. Once the wheelchair landed safely the ramps will be on the backside of the wheel chair. The ramps can be then take upside for putting back on the side frame and locked firmly with the lock nuts.

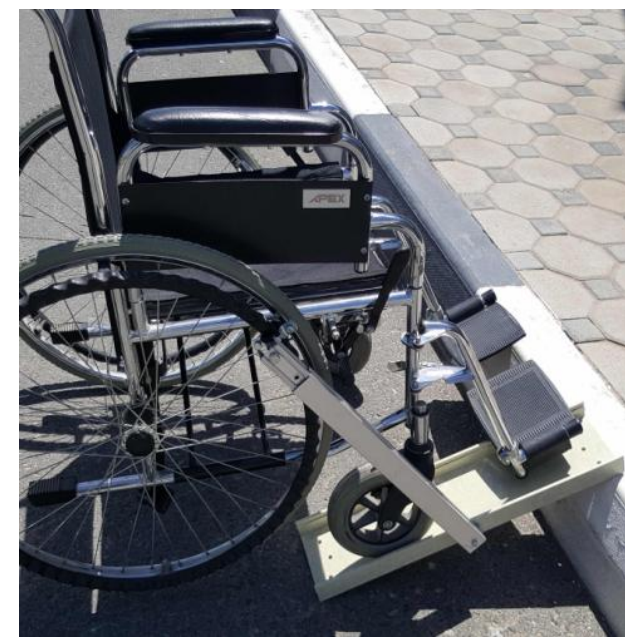

Fig.3 Prototype using Glass Reinforced Plastic (GRP)

Before the final fabrication a prototype developed using Glass Reinforced Plastic(GRP) tray and rectangular tubes for testing and deciding on the final design.

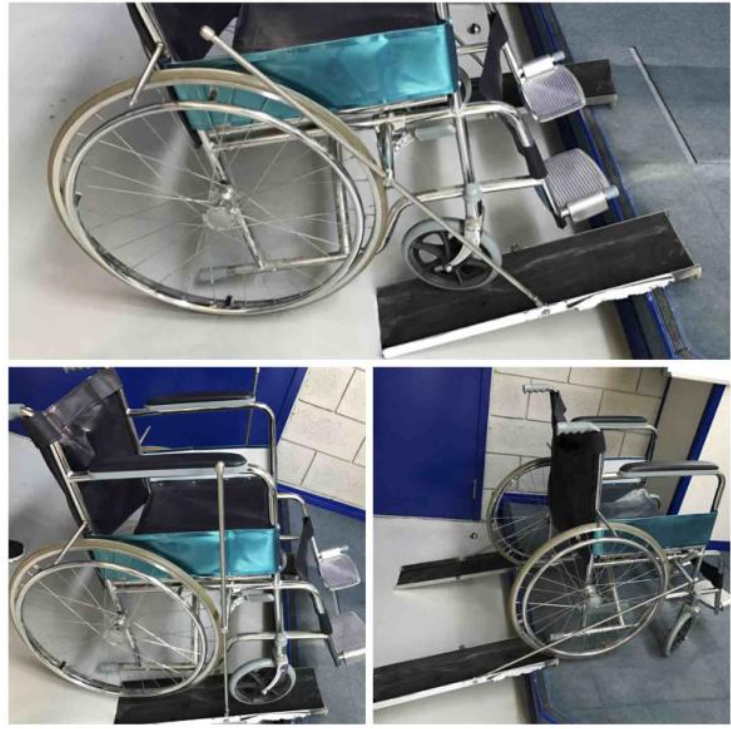

Fig.4 Wheelchair climbing curb using ramp attachment.

The important advantages of ramp attachment design are

- Most economical way of adding ramp feature to any available wheelchairs.

- Removes the difficulty of disabled people to move around.

- Can be used in home for transferring old age people from room to vehicles with less effort.

- Can be adopted for shopping trolleys.

- Cost effective

- Less maintenance

- Flexible to modifications.

The ramp attachment is fabricated with inexpensive and light-weight materials made them easy to operate and maintain. The design can be improvised as a future scope of work by adding pneumatic cylinders for automatic folding and deployment of ramp attachment.

\section{CONCLUSION}

The paper proposed an economic way of improving the capabilities of manual wheelchair that eliminates the difficulty of climbing over curbs. The design can be implemented with less production cost and can be included to the existing designs. This climbing aid need to be undergo various field tests and analysis to improvise the stability and durability. 


\section{REFERENCES}

[1] Roger.N.White B.S, Andrew Y.J. Szeto, Harry.A. Hogan, "A practical curb climbing aid for wheelchair bound paraplegic persons ( A progress report)", Bulletin of prosthetics research, BPR 10-34 (Volume 17 No.2), 1980, Pages 13

[2] M. Lawn and T. Shiatsu, "Modeling of a stair climbing wheelchair mechanism with high single-step capability," IEEE Transactions on Neural Systems and Rehabilitation Engineering, vol. 11, no. 3, pp. 323-332, Sept. 2003

[3] R Rajasekar, K P Pranavkarthik, RPrashanth, S Senthil Kumar and A Sivakumar, "Design and Fabrication of Staircase Climbing Wheelchair", IJMRRR, (2013), 320-323.

[4] Jeyabalaji C, Vimalkhanna V, Avinashilingam N, Mohamed Zeeshan M A and Harish Kumar N, "Design of Low Cost Stair Climbing Robot Using Arduino", Int. Journal of Engineering Research and Applications ,ISSN : 2248-9622, Vol. 4, Issue 10( Part - 3), October 2014, pp.15-18.

[5] Kalantari, A. Mihankhah, E. Moosavian, S.A.A. "Safe Autonomous Stair Climbing For A Tracked Mobile Robot Using A Kinematics Based Controller" IEEE/ASME International Conference On Advanced Intelligent Mechatronics, 2009.

[6] Medical Devices Agency. Guidance on the safe transporta- tion of wheelchairs, MDA DB2001(03). ISBN 1-84182-8. London: Medical Devices Agency; 2001.
[13] M. Lawn, "A robotic hybrid wheelchair for operation in the real world," in Computer Science Center, Nagasaki Institute of Applied Science, No. 8, pp. 65-77, 1997. M. Lawn, T. Takeda, "Development of a 20 DOF wheelchair for operation in a barrier present environment," Proc. 8th ISMCR Int.1 Symp. Measurement and Control in Robotics, Prague, Czech Republic, pp. 411416, 1998.

International Journal of Engineering Research and Applications (IJERA) is UGC approved Journal with Sl. No. 4525, Journal no. 47088. Indexed in Cross Ref, Index Copernicus (ICV 80.82), NASA, Ads, Researcher Id Thomson Reuters, DOAJ.

Arish Ibrahim. "Design and Fabrication of Ramp Attachment for Wheelchair." International Journal of Engineering Research and Applications (IJERA) 7.7 (2017): 46-48. 